\title{
Investigating the possibility of a human component in various pacific decadal oscillation indices
}

\author{
Céline Bonfils • Benjamin D. Santer
}

Received: 12 February 2010/Accepted: 19 September 2010/Published online: 9 October 2010

(C) The Author(s) 2010. This article is published with open access at Springerlink.com

\begin{abstract}
The pacific decadal oscillation (PDO) is a mode of natural decadal climate variability, typically defined as the principal component of North Pacific sea surface temperature (SST) anomalies. To remove any global warming signal present in the data, the traditional definition specifies that monthly-mean, global-average SST anomalies are subtracted from the local anomalies. Differences in the warming rates over the globe and the PDO region may therefore be aliased into the PDO index. Here, we examine the possibility of a human component in the PDO, considering three different definitions. The implications of these definitions are explored using SSTs from both observations and simulations of historical and future climate, all projected onto (definition-dependent) observed PDO patterns. In the twenty first century scenarios, a systematic anthropogenic component is found in all three PDO indices. Under the first definition-in which no warming signal is removed - this component is so large that it is also statistically detectable in the observed PDO. Using the second/traditional definition, this component is also large, and arises primarily from the differential warming rates predicted in the North Pacific and over global oceans. Removing the spatial average SST signal in the PDO region (in the third definition) partially solves this problem, but a human signal persists because the predicted pattern of SST response to human forcing projects strongly onto the PDO pattern. This illustrates the importance of separating internally-generated and externally-forced components in the PDO, and suggests that caution should be exercised in
\end{abstract}

C. Bonfils $(\bowtie) \cdot$ B. D. Santer

Lawrence Livermore National Laboratory,

Livermore, CA 94550, USA

e-mail: bonfils2@1lnl.gov using PDO indices for statistical removal of "natural variability" effects from observational datasets.

Keywords Climate simulations - Pacific decadal oscillation - Mode of decadal variability - Trend . Sea surface temperatures - Detection of regional climate change

$\begin{array}{ll}\text { Abbreviations } \\ \text { PDO } & \text { Pacific decadal oscillation } \\ \text { SST } & \text { Sea surface temperature } \\ \text { EOF } & \text { Empirical orthogonal function } \\ \text { S-PDOP } & \text { Spatial PDO pattern } \\ \text { ERSST } & \text { Extended reconstructed SST dataset } \\ \text { HadISST } & \text { Hadley center sea ice and SST dataset } \\ \text { 20CEN } & \text { Twentieth century run }\end{array}$

\section{Introduction}

Climate indices provide a means of distilling complex patterns of spatio-temporal variability into simple forms. Indices such as the southern oscillation index (SOI) or the pacific decadal oscillation index (PDO, Hare 1996; Zhang et al. 1997; Mantua et al. 1997), are often used to represent the behavior of modes of natural internal variability. Such modes of "unforced" variability share common features: they are thought to arise from interactions between the coupled atmosphere/ocean system; they display preferred spatial structures; and they can demonstrate sudden "regime shifts" and complex low-frequency behavior. Many of the features of observed modes of natural internal variability can be found in paleoclimate proxies and 
replicated by current climate models (Biondi et al. 2001; Hunt 2008; Pierce et al. 2000).

The PDO index is associated with the interdecadal variability of sea surface temperatures (SSTs) in the northern Pacific Ocean. It is distinguished by abrupt phase shifts (e.g., in 1925, 1947, and 1977), and can have a "far field" influence on climate through atmospheric teleconnections (Mantua and Hare 2002). A large variety of natural systems (e.g., salmon productivity, drought-induced fires, annual river flow, onset of spring, etc.) and atmospheric variables have been related to "natural" fluctuations in the PDO (Mantua et al. 1997; Schoennagel et al. 2005; Neal et al. 2002; Cayan et al. 2001). Previous research studies have relied on PDO and El Niño indices to show that, over mountainous areas of the western US, climate variability alone cannot explain the declining snowpack, the decrease in the fraction of precipitation arriving as snow, and the earlier runoff from snowmelt (Mote 2003; Knowles et al. 2006; Stewart et al. 2005; Pierce et al. 2008; Bonfils et al. 2008).

While knowledge of the current state of the PDO can be very valuable for seasonal and annual climate forecasts, for assessments of changes in natural systems (Mantua and Hare 2002; McCabe and Dettinger 2002) and for decadal climate predictions (Latif and Barnett 1996), the physical mechanisms responsible for low-frequency changes in the PDO are not yet fully understood (e.g., Nakamura et al. 1997; Trenberth and Hurrell 1994). Furthermore, it is entirely plausible that external forcings (e.g., greenhouse gas and sulfate aerosol forcing) have influenced both north Pacific SSTs and the PDO index itself. Meehl et al. (2009), ${ }^{1}$ for example, could only explain the prominent regime shift in Pacific SSTs in the mid-1970s by means of a combination of internally generated variability and anthropogenic forcing.

To date, the PDO index has primarily been defined in two different ways. Under the first definition, the PDO is simply the first principal component of monthly SST anomalies in the Pacific Ocean poleward of $20^{\circ} \mathrm{N}$ (e.g., Hunt 2008; Pierce et al. 2008; McCabe and Dettinger 2002; Sun and Wang 2006; Davis 1976). Under the second definition (the current "official" or "traditional" definition of the PDO; Zhang et al. 1997; Mantua and Hare 2002; Knowles et al. 2006), monthly-mean global-average SST anomalies are first removed from local anomalies prior to calculation of principal components. The rationale for this subtraction is to "separate this pattern of variability from

\footnotetext{
${ }_{1}^{1}$ We focus in this paper on the PDO index, and hence on North Pacific SSTs. Other studies (such as Meehl et al. 2009) have devoted their attention to the Interdecadal Pacific Oscillation (IPO, Power et al. 1999; Meehl and $\mathrm{Hu}$ 2006; McGregor et al. 2007), which is defined as the first EOF of detrended SSTs for the entire Pacific basin (or the second EOF of the non-detrended Pacific SST data). The behavior of PDO and IPO indices is closely related.
}

any "global warming" signal that may be present in the data". 2 Since the true, underlying response of SSTs to human-caused changes in greenhouse gases is uncertain, Zhang et al. (1997) effectively assumed that observed changes in global-mean SST provided a reasonable estimate of this response. They also made a second, implicit assumption that the SST response to anthropogenic forcing is spatially uniform. We now know that this second assumption may be problematic (Meehl et al. 2007). Under the Zhang et al. (1997) PDO definition, if any long-term, systematic difference in the warming rates of global-mean SST and SST in the PDO region exists, it will be aliased into the PDO index.

In this study, we investigate whether the PDO index contains a human signature. Our analysis considers both historical and projected future changes in SST in the PDO region. In the latter case, the imposed anthropogenic forcing is substantially larger than the estimated anthropogenic forcing over the twentieth century, thus making it easier to separate forced and unforced SST variability. We examine the behavior of the PDO using: (1) three different PDO definitions, (2) two recent observational SST datasets, (3) a suite of model simulations of twentieth and twentyfirst century climate change, and (4) selected multi-century unforced control runs.

\section{Model and observational data}

This work relies on two recent observational SST datasets to estimate the spatial structure and temporal evolution of the PDO: the UK Meteorological Office Hadley Centre Sea Ice and SST dataset (HadISST1.1, Rayner et al. 2006), and version $3 b$ of the extended reconstructed SST dataset (ERSST3b, Smith et al. 2008) developed at the National Climatic Data Center (see Appendix 1 for more information on the observational datasets). Both datasets show a similar slowly-evolving warming signal in the PDO region (Fig. 1). Using those two datasets allows us to test the robustness of results to structural uncertainties in the observations. These are uncertainties that arise from the sparse data coverage, the different reconstruction procedures used to infill missing SST data, and adjustments for non-climatic influences (such as changes in measurements practices, observational times, and instrumentation).

PDO indices from model simulations of historical and future climate change are estimated using results from 17 different climate models in the CMIP-3 archive (Table 1). The set of 17 models analyzed here includes eight models (SELECT) that successfully capture key spatial and

\footnotetext{
$\overline{2}$ This quote is taken from the current official PDO website: http://jisao.washington.edu/pdo/PDO.latest.
} 


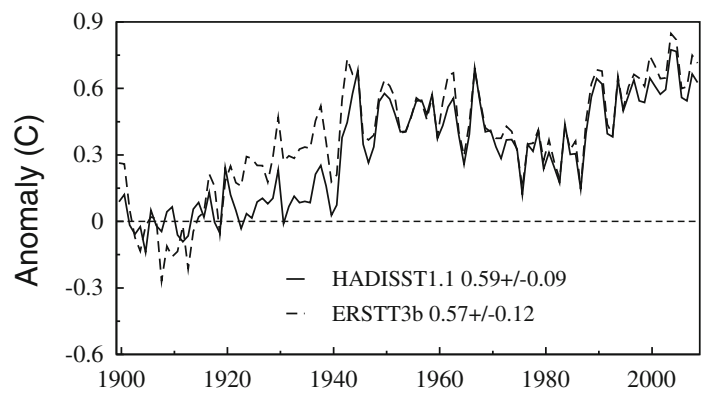

Fig. 1 Observed time series of annual mean, spatially averaged SST anomalies in the PDO region $\left(245-115^{\circ} \mathrm{W}, 20-60^{\circ} \mathrm{N}\right)$ from HadISST1.1 and ERSST3b regridded datasets. Both SST anomalies are defined relative to climatological monthly means over 1900 through 1909 (chosen for visual display purposes only). All trends (in ${ }^{\circ} \mathrm{C} /$ century), calculated over the period 1900-2009, are significantly different from zero at the $1 \%$ level $(p<0.01)$

temporal characteristics of the PDO for the current climate (Overland and Wang 2007). Results from the multi-model CMIP-3 archive supply valuable information on structural uncertainties in both the applied twentieth and twenty-first century external forcings and the simulated climate response to these forcings.
All twentieth century (20CEN) simulations include estimated historical changes in various types of anthropogenic forcing. Half of the 20CEN simulations (and seven of the eight SELECT models) also include some form of solar and volcanic forcing. The twenty-first century climate projections are based on the A2 scenario for future greenhouse gas and aerosol emissions. We also analyzed multicentury pre-industrial control (CTL) simulations performed with the SELECT models in order to estimate the sampling distribution of PDO trends arising from internal climate variability alone. Further details of the models and the SELECT models are provided in Appendix 2.

\section{PDO definitions}

The official PDO index (Mantua et al. 1997) is based on "residual" monthly-mean SST anomalies in the North Pacific region (poleward of $20^{\circ} \mathrm{N}$ ). The residual anomalies are obtained for each grid point and for each month by (1) removing the monthly climatology computed over the stipulated base period 1900-1993, and (2) subtracting the timedependent global-mean SST anomaly for this particular
Table 1 CMIP3 climate models and their number of 20CEN and A2 realizations

\footnotetext{
* Model including some representation of solar and volcanic effect on climate

In bold the eight SELECT models that successfully capture key spatial and temporal characteristics of the PDO for the current climate
}

\begin{tabular}{|c|c|c|c|}
\hline Model name & 20CEN & A2 & Modeling groups \\
\hline $\begin{array}{l}\text { CCCma-CGCM3.1 } \\
\text { (T47) }\end{array}$ & 5 & 5 & Canadian Centre for Climate Modelling and Analysis, Canada \\
\hline GFDL-CM2.0* & 3 & 1 & Geophysical Fluid Dynamics Laboratory, USA \\
\hline GFDL-CM2.1* & 3 & 1 & Geophysical Fluid Dynamics Laboratory, USA \\
\hline MIROC3.2(medres)* & 3 & 3 & $\begin{array}{l}\text { Center for Climate System Research, National Institute for } \\
\text { Environmental Studies, and Frontier Research Center for Global } \\
\text { Change, Japan }\end{array}$ \\
\hline MIUB/ECHO-G* & 5 & 3 & $\begin{array}{l}\text { Meteorological Institute of the Univ. of Bonn, Meteorological } \\
\text { Research Institute of the Korean Meteorological Agency, and } \\
\text { Model and Data group, Germany/Korea }\end{array}$ \\
\hline MRI-CGCM2.3.2* & 5 & 5 & Meteorological Research Institute \\
\hline CCSM3.0* & 8 & 4 & National Center for Atmospheric Research, USA \\
\hline UKMO-HadCM3* & 1 & 1 & $\begin{array}{l}\text { United Kingdom Meteorological Office Hadley Centre for Climate } \\
\text { Prediction and Research, UK }\end{array}$ \\
\hline BCCR-BCM2.0 & 1 & 1 & Bjerknes Center for Climate Research, Norway \\
\hline CNRM-CM3 & 1 & 1 & $\begin{array}{l}\text { Météo-France/Centre National de Recherhces Météorologiques, } \\
\text { France }\end{array}$ \\
\hline CSIRO-Mk3.0 & 3 & 1 & $\begin{array}{l}\text { Commonwealth Scientific and Industrial Research Organization } \\
\text { (CSIRO) Atmospheric Research, Australia }\end{array}$ \\
\hline GISS_ER* & 9 & 1 & Goddard Institute for Space Studies, USA \\
\hline INM-CM3.0 & 1 & 1 & Institute for Numerical Mathematics, Russia \\
\hline IPSL_CM4 & 1 & 1 & Institute Pierre Simon Laplace, France \\
\hline ECHAM5/MPI-OM & 3 & 3 & Max-Planck Institute for Meteorology, Germany \\
\hline $\mathrm{PCM}^{*}$ & 4 & 4 & National Center for Atmospheric Research, USA \\
\hline UKMO-HadGEM1 & 1 & 1 & $\begin{array}{l}\text { Meteorological Office Hadley Centre for Climate Prediction and } \\
\text { Research, UK }\end{array}$ \\
\hline SELECT models & 33 & 23 & \\
\hline ALL models & 57 & 37 & \\
\hline
\end{tabular}


month. The dominant EOF of these residuals, calculated over the 94 year base period, is described as the observed "spatial PDO pattern" (S-PDOP). The full PDO time series for the entire analysis period is then obtained by projecting the residual anomalies onto the eigenvectors of the S-PDOP (computed over 1900-1993). This procedure facilitates monthly updating of the PDO time series without modifying past PDO index values, and allows users to employ alternate observational SST datasets (see Appendix 3.1) using the original S-PDOP pattern. Here, we explore two alternatives to the "official" PDO definition (which we refer to as "definition 2"). Definition 1 is a simplified version of the official PDO index, which does not involve removal of a global-mean, monthly-mean SST signal prior to the EOF analysis. In definition 3, we subtract the regional-mean rather than the global-mean SST anomalies. The intent is to avoid aliasing differential warming rates over the North Pacific and the global oceans into the definition of the PDO.

For each definition, we computed the leading EOF from the HadISST1.1 observed SST anomalies over 1900-1993, and thereby obtained three different spatial PDO patterns $\left(\mathrm{S}-\mathrm{PDOP}_{1},{\mathrm{~S}-\mathrm{PDOP}_{2} \text {, and S-PDOP }}_{3}\right.$ ). Observed SST anomalies for the entire analysis period (computed as specified under each definition) were then projected onto their corresponding S-PDOP, resulting in three observed PDO indices. Similarly, we projected the model SST anomalies (computed as specified in each definition) from the 20CEN, A2, and SELECT CTL integrations ${ }^{3}$ onto their respective observed S-PDOP (see Appendixes 3.1 and 3.2 for more details). The entire procedure is then repeated using the ERSST3b dataset. Since the phasing of the internally-generated component of the PDO is random in different realizations, the ensembleaveraging of SST anomalies over a sufficiently-large number of 20CEN and A2 realizations should help to reveal any underlying externally-forced component in the PDO.

\section{Results}

\subsection{Observed PDO patterns and PDO time series}

We first analyze the spatial characteristics of the three S-PDOPs obtained using the HadISST1.1 dataset (Fig. 2a-c). All three S-PDOPs capture the typical structural features of the spatial PDO pattern. A pool of anomalously cool water in the central North Pacific is surrounded by a horseshoeshape region of anomalously warm waters (by convention, this is the positive phase of the PDO). The amplitude and

\footnotetext{
${ }^{3}$ SST anomalies from A2 simulations have been defined relative to the monthly-mean climatology over the period January 2000December 2009. The climatology used for anomaly definition in the CTL runs was calculated over the first 10 years of the integrations.
}

the sign of the eigenvectors vary slightly with the index definition. This dominant mode explains $\sim 27,30$, and $28 \%$ of the SST variance in the case of S-PDOP $1, \mathrm{~S}_{1} \mathrm{PDOP}_{2}$ and $\mathrm{S}-\mathrm{PDOP}_{3}$, respectively. The weighted spatial average of the eigenvectors is negative for $\mathrm{S}_{-\mathrm{PDOP}}$ and for $\mathrm{S}-\mathrm{PDOP}_{2}$, but (by definition) is zero in the case of $\mathrm{S}_{-\mathrm{PDOP}_{3}}$ (Table 2). This information will be important for understanding the sign of projected PDO trends.

We then analyzed the three observed PDO indices computed with HadISST1.1 data (Fig. 3a-b). All three indices show pronounced variability on multi-decadal timescales (Fig. 3a). As expected, the $\mathrm{PDO}_{2}$ (red) time series correlates best with the official PDO index ( $r=0.93$, Table 2). ${ }^{4}$ The $\mathrm{PDO}_{1}$ (black) index exhibits a negative trend $\left(-0.86 \pm 0.40^{\circ} \mathrm{C} /\right.$ century) over the period $1900-2009$ that is significantly different from zero $(p=0.04) .{ }^{5}$ This trend arises from projecting the slowly-evolving warming signal in the PDO region (shown in Fig. 1) onto the predominantly negative $\mathrm{S}-\mathrm{PDOP}_{1}$. After subtracting the time-evolving global and regional mean SST changes (definitions 2 and 3), there is no overall statistically significant trend in either the $\mathrm{PDO}_{2}$ or $\mathrm{PDO}_{3}$ time series (Table 2).

The difference between the $\mathrm{PDO}_{2}$ and $\mathrm{PDO}_{1}$ indices is large and displays a clear century-time-scale positive trend. The difference largely reflects the time-dependent globallyaveraged SST anomalies subtracted in definition 2 (brown and blue dotted lines in Fig. 3b; $r=0.99$ ). The "betweenindex" differences resulting from different index definitions are significantly larger than the differences attributable to observational SST uncertainties (defined as \pm one temporal standard deviation of the difference time series between the HadISST1.1 and ERSST3b $\mathrm{PDO}_{3}$, and represented by the horizontal lines in Fig. 3b). Similarly, the differences between the $\mathrm{PDO}_{3}$ and $\mathrm{PDO}_{2}$ time-series are correlated with the differences between SST anomalies averaged over the PDO region and the global oceans ( $r=0.76$; magenta and blue dashed lines in Fig. 3b). When the PDO region warms more rapidly than the globe (during the period 1900-1955 and after the last PDO shift in 1977), the residual warming signal included in the definition 2-driven SST anomalies is projected onto the predominantly negative $\mathrm{S}-\mathrm{PDOP}_{2}$, thus introducing differences between $\mathrm{PDO}_{2}$ and $\mathrm{PDO}_{3}{ }^{6}$ Between 1955 and 1975, this dissimilarity in global and regional temperatures decreases, as does the difference between the $\mathrm{PDO}_{2}$ and $\mathrm{PDO}_{3}$ indices. For the $\mathrm{PDO}_{2}$ and $\mathrm{PDO}_{3}$ index pair, the inter-definitional differences are

\footnotetext{
${ }^{4}$ These two time series are not exactly identical owing to small differences in the datasets and processing options (see Appendix 3.1).

5 The $\mathrm{PDO}_{1}$ index is predominantly in the cold phase at the end of the record. This occurs because the time series have been plotted relative to the period $1900-1909$.

${ }^{6}$ By definition, this residual warming is not included in the definition-3 driven SST anomalies. .
} 
Fig. 2 Spatial PDO patterns of SST residuals using a definition 1 (simple SST anomalies prior the EOF analysis, $\mathrm{S}-\mathrm{PDOP}_{1}$ ), b definition 2 (global mean SST removed, $\left.\mathrm{S}-\mathrm{PDOP}_{2}\right)$, and c definition 3 (regional mean SST removed, $\mathrm{S}-\mathrm{PDOP}_{3}$ ). All EOFs (in ${ }^{\circ} \mathrm{C}$ per standard deviation of the index timeseries) are based on HadISST1.1 dataset and the base period 1900-1993 (as in the official definition) (a) S-PDOP $(26.61 \%)$

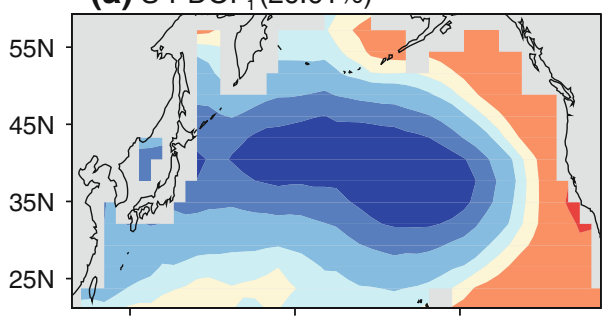

(c) $\mathrm{S}-\mathrm{PDOP}_{3}(28.32 \%)$

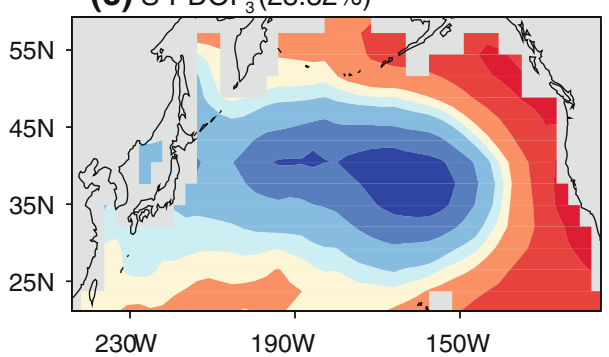

(b) S-PDOP $2(30.16 \%)$
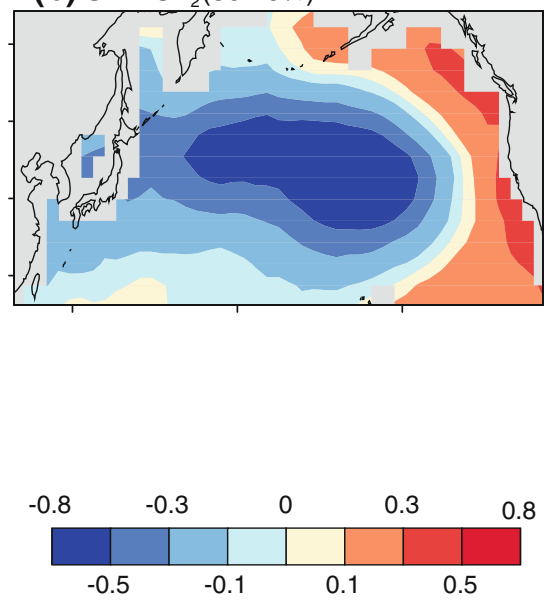

Table 2 Statistics on observed S-PDOPs and observed PDOs

\begin{tabular}{|c|c|c|c|c|c|c|c|c|c|}
\hline & \multicolumn{3}{|c|}{ Spatial average $\left({ }^{\circ} \mathrm{C}\right)$} & \multicolumn{3}{|c|}{ Trend over $1900-2009\left({ }^{\circ} \mathrm{C} /\right.$ century $)$} & \multicolumn{3}{|c|}{ Correlation with official PDO } \\
\hline & S-PDOP1 & S-PDOP2 & S-PDOP3 & PDO1 & $\mathrm{PDO} 2$ & PDO3 & PDO1 & $\mathrm{PDO} 2$ & PDO3 \\
\hline HadISST1.1 & -0.165 & -0.154 & 0 & $-0.86 \pm 0.40^{* *}$ & $0.07 \pm 0.42$ & $0.23 \pm 0.41$ & 0.876 & 0.930 & 0.901 \\
\hline ERSST3b & -0.178 & -0.152 & 0 & $-0.97 \pm 0.41 * *$ & $0.08 \pm 0.42$ & $-0.07 \pm 0.41$ & 0.810 & 0.912 & 0.904 \\
\hline
\end{tabular}

The presence of one, two, or three asterisks indicates whether the trends are significant at the 10, 5 and $1 \%$ level, respectively (see Santer et al. 2000)

smaller than the differences arising from observational uncertainties (i.e., the horizontal lines in Fig. 3b).

All these results are qualitatively similar when using the ERSST3b dataset (see Appendix 4.1 and Table 2). We also note that for definitions 2 and 3, results are also insensitive to the base period chosen. In contrast, the trend in the $\mathrm{PDO}_{1}$ index is proportional to the spatial average of the

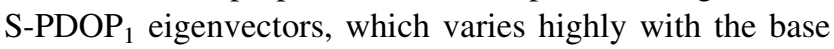
period employed (Appendix 4.1).

\subsection{Model-based historical PDO estimates}

We then examined the PDO indices computed from the 20CEN SELECT simulations (Fig. 3c-d). As in the observations, the PDO indices from individual 20CEN realizations display large decadal variability (not shown). Averaging over realizations and models (hereafter denoted as the multimodel ensemble mean, or MME) markedly reduces the internally-generated noise, increases the signal-to-noise ratio, and reveals a possible PDO response to external forcing. ${ }^{7}$

\footnotetext{
${ }^{7}$ In theory, trends in a natural mode of variability should (with a large enough number of realizations) produce a sampling distribution with an average trend of zero.
}

As in the observations, the MME $\mathrm{PDO}_{1}$ index shows a century-scale negative trend over the period 1900-1999 $\left(-0.36 \pm 0.16^{\circ} \mathrm{C} /\right.$ century, $p=0.03$; black line in Fig. $\left.3 \mathrm{c}\right)$. Another similarity with the observed results is that the difference between the simulated $\mathrm{PDO}_{2}$ and $\mathrm{PDO}_{1}$ indices displays a positive trend over the twentieth century and is highly correlated with the MME globally-averaged SST anomalies (brown and blue-dotted lines in Fig. 3d). This difference is larger than observational uncertainties (i.e., the horizontal lines). Finally, (and again as in the observed case), the difference time series between the simulated $\mathrm{PDO}_{2}$ and $\mathrm{PDO}_{3}$ time series correlates well with the differential warming of the PDO and the globe inferred from the MME (magenta and blue-dashed lines in Fig. 3d).

\subsection{Model-based estimates of future behavior of the PDO}

In the A2 runs, greenhouse gas forcing is larger than over the twentieth century. The larger forcing more clearly reveals the effect of continued anthropogenic warming on the various definitions of the PDO (Fig. 3e-f). One striking result is that in the MME, all three PDO indices exhibit statistically significant century-scale negative trends over the twentyfirst century (Fig. 3e). The origin of the trend differs for each 


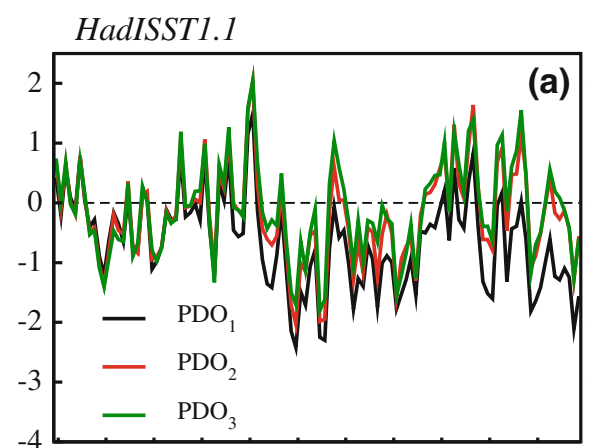

$20 C E N$
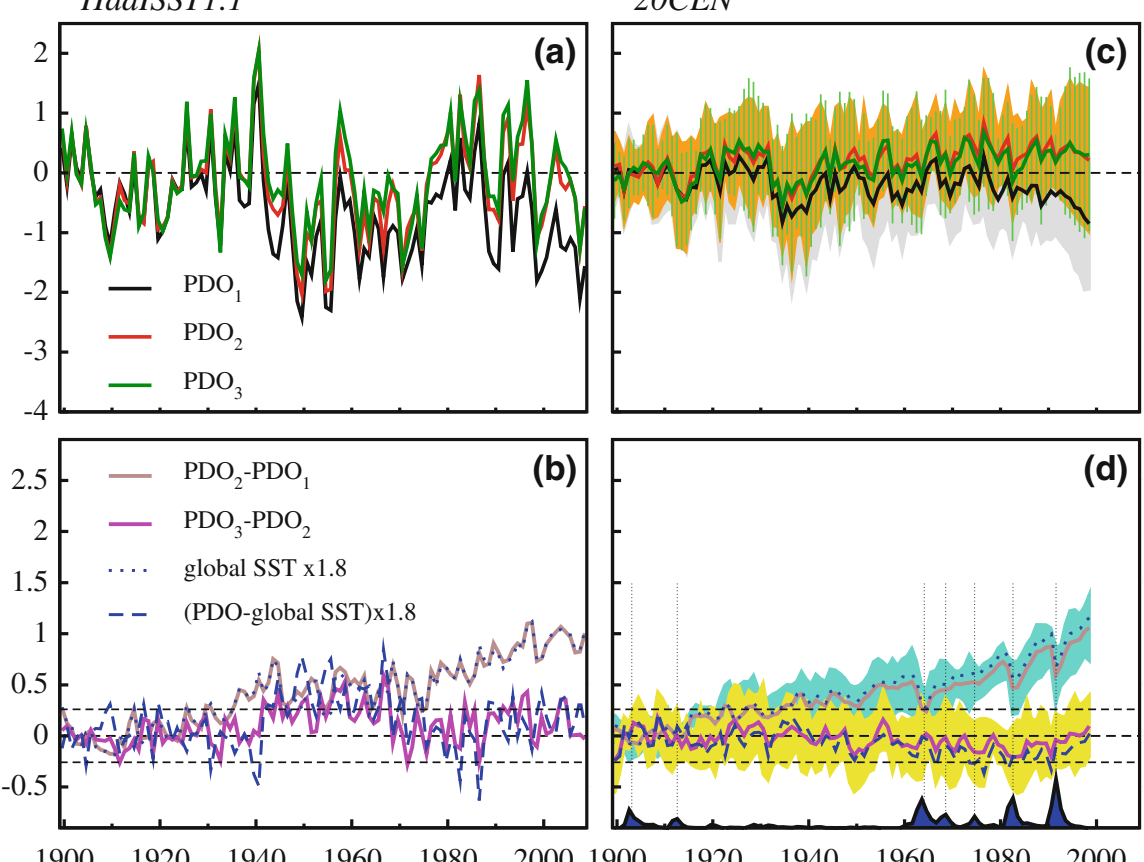

$A 2$
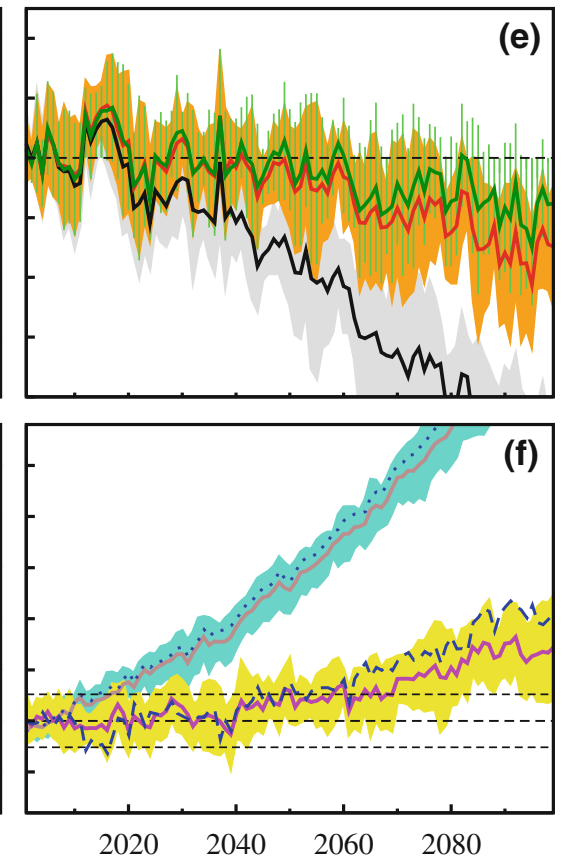

Fig. 3 Annual mean $\mathrm{PDO}_{1}, \mathrm{PDO}_{2}$, and $\mathrm{PDO}_{3}$ time-series using a the HadISST1.1 dataset, $\mathbf{c}$ the average of the 8 SELECT 20CEN ensembles; and $\mathbf{e}$ the average of the 8 SELECT A2 ensembles. The grey, orange and green envelops in panels $\mathbf{c}$, and $\mathbf{e}$ are the minimum/maximum intervals for the simulated $\mathrm{PDO}_{1}, \mathrm{PDO}_{2}$ and $\mathrm{PDO}_{3}$. The difference between those PDO time-series are indicated in panels $\mathbf{b}, \mathbf{d}$ and $\mathbf{f}$ (along with their $1 \sigma$ confidence intervals in panels $\mathbf{d}$ and $\mathbf{f}$ ). The annual mean, globallyaveraged SST anomalies (blue-dotted line) and the difference between SST anomalies averaged over the globe and the PDO region (bluedashed line) are also displayed, both in ${ }^{\circ} \mathrm{C}$ and multiplied by 1.8 to adjust their variance to that of the interdefinition differences. The dashed horizontal lines in $\mathbf{b}, \mathbf{d}$, and $\mathbf{f}$ is a measure of observational

index. In the case of the $\mathrm{PDO}_{1}$ index (black line), the significant negative trend $\left(-6.12 \pm 0.39^{\circ} \mathrm{C} /\right.$ century, $p<0.001)$ arises mainly because the large anthropogenic warming in the northern Pacific Ocean simulated in the A2 uncertainties represented as one temporal standard deviation of the difference time series between the HadISST1.1 and ERSTT3b $\mathrm{PDO}_{3}$. In panel d, the observed changes in estimate of stratospheric aerosol optical depth (filled blue time-series; Sato et al. 1993) indicates the times of major volcanic eruptions; they are in phase with the globalaverage SST times series (Thompson et al. 2008), hence with some of variability in the simulated $\mathrm{PDO}_{2}-\mathrm{PDO}_{1}$ time-series. All projected SST anomalies are defined relative to climatological monthly means over 1900-1909 for the historical period and over 2000-2009 for the future period. The reference period was chosen for visual display purposes only (with no impact on trend analyses but with possible change the partition of positive and negative phases) (a)

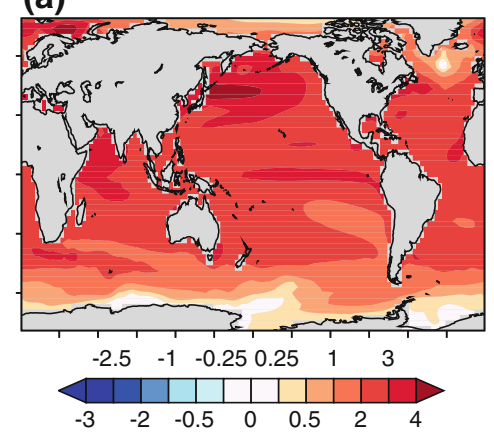

(b)

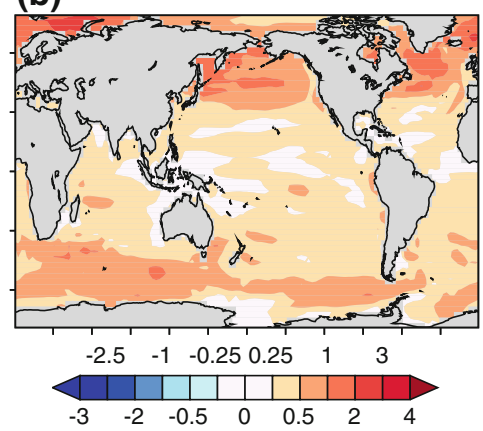

(c)

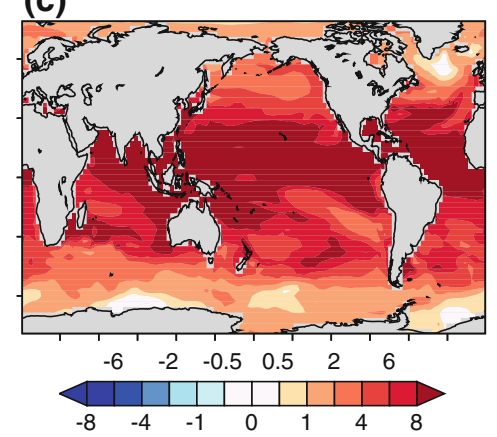

Fig. 4 a Multi-ensemble average of SST trends over the period 2001-2099 (in ${ }^{\circ} \mathrm{C} /$ decade) using the SELECT models (called hereafter signal). b Standard deviation of the trends across models (called hereafter noise), c Signal-to-noise ratio. Regions with a ratio runs is projected onto the predominantly negative S-PDOP 1 (Fig. 4a).

For the $\mathrm{PDO}_{2}$ index (red line), however, the negative trend $\left(-2.00 \pm 0.22^{\circ} \mathrm{C} /\right.$ century, $\left.p<0.001\right)$ results from 
the projection of a residual human-induced SST warming onto the predominantly negative $\mathrm{S}-\mathrm{PDOP}_{2}$. This residual warming occurs because the ocean surface is predicted to warm more rapidly in the PDO region than globally (see Fig. 4a). This differential warming in the twenty-first century is a robust feature of model results (Fig. 4c).

Even under definition 3 (green line), a negative, statistically-significant trend in the $\mathrm{PDO}_{3}$ index persists $\left(-1.18 \pm 0.20^{\circ} \mathrm{C} /\right.$ century, $\left.p<0.01\right)$. This negative trend occurs because the pattern of SST response in the A2 runs is similar to the $\mathrm{PDO}_{3}$ pattern (and thus projects strongly onto the latter), but the forced SST response to combined greenhouse-gas and sulfate aerosol forcing is of opposite sign to the $\mathrm{PDO}_{3}$ pattern in the central "core" of the PDO region (compare Figs. 2c, 4a).

Finally, we note that both of the "between-definition" differences $\left(\mathrm{PDO}_{2}\right.$ minus $\mathrm{PDO}_{1}$, and $\mathrm{PDO}_{3}$ minus $\left.\mathrm{PDO}_{2}\right)$ are predicted to be larger than the current observational uncertainties. The behavior of the PDO in the twenty-first century simulations is relatively insensitive to observational uncertainties in the S-PDOP patterns, or to the set of models chosen for analysis (see Appendix 4.2 and Table 3).

\subsection{Comparison of historical and future trends} with unforced trends

Can the historical PDO trends (in model and observations) and future PDO trends (in the A2 runs) be explained by climate noise alone? To address this question, we compared the century time-scale PDO changes in the observations and in the historical and future simulations with the unforced changes in the PDO estimated from the model control runs.

To perform these comparisons, we computed the distribution of PDO trends; 1) over 1900-1999 (from the 20CEN runs); 2) over 2000-2099 (from the A2 runs); and 3) from overlapping 100-year segments of the CTL integrations. We then estimated whether (1) the observed PDO trends could be due to climate noise alone; and (2) the distributions of PDO trends inferred from the 20CEN (or A2) runs differ from the distribution of unforced trends. This analysis was performed independently for each definition, using the SELECT models only (Fig. 5). Further details regarding the trend comparisons are provided in Appendices 5.1 and 5.2.

In the case of definition 1 of the PDO (Fig. 5, left panels), we found that both the HadISST1.1 and NOAA3b $\mathrm{PDO}_{1}$ trends are incompatible with changes arising from climate noise alone (at the 5\% level for HadISST1.1 and $10 \%$ level for NOAA3b), but consistent with $\mathrm{PDO}_{1}$ trends obtained from the 20CEN runs. The distributions of 20CEN and $\mathrm{A} 2 \mathrm{PDO}_{1}$ trends are statistically different from the distribution of unforced PDO trends (at the 5\% significance level). These results suggest that an externallyforced component is detectable in the observed $\mathrm{PDO}_{1}$.

For definitions 2 and 3, the PDO trends projected to occur over the twenty-first century in the A2 scenario cannot be explained by climate noise alone, and are likely to contain an anthropogenic component. However, historical trends in the simulated and observed $\mathrm{PDO}_{2}$ and $\mathrm{PDO}_{3}$ indices over the twentieth century were not inconsistent with model-based estimates of internal noise.

Because of the increase in anthropogenic forcing in the second half of the end of the twentieth century, we repeated this analysis for a 32-year period starting after the last observed PDO shift of 1977. For this more recent period, all observed PDO trends over 1978-2009 can be distinguished from internally-generated variability, independent of the PDO definition employed (at the 5\% level for definition 1 and at the $10 \%$ level for definitions 2 and 3). We note that on the 32-year timescale, the more rapid warming

Table 3 Trends in the multi-ensemble averaged PDO indices for two sets of models (the SELECT or ALL available models) and for two weighting options (the "unweighted" option gives equal weight to each model while in the "weighted" option, the model weight is commensurate to the number of realizations)

\begin{tabular}{|c|c|c|c|c|c|c|c|}
\hline \multirow[t]{2}{*}{ Set of models } & \multirow[t]{2}{*}{ Dataset } & \multicolumn{3}{|l|}{ 20CEN trend } & \multicolumn{3}{|l|}{ A2 trend } \\
\hline & & PDO1 & $\mathrm{PDO} 2$ & PDO3 & PDO1 & PDO2 & $\mathrm{PDO} 3$ \\
\hline SELECT and & HadISST1.1 & $-0.36 \pm 0.16^{* *}$ & $0.49 \pm 0.13 * * *$ & $0.39 \pm 0.15^{* *}$ & $-6.12 \pm 0.39 * * *$ & $-2.00 \pm 0.22 * * *$ & $-1.18 \pm 0.20 * * *$ \\
\hline Unweighted & ERSST3b & $-0.37 \pm 0.15^{* *}$ & $0.46 \pm 0.13 * * *$ & $0.37 \pm 0.15^{* *}$ & $-5.90 \pm 0.39 * * *$ & $-1.93 \pm 0.22 * * *$ & $-1.20 \pm 0.20 * * *$ \\
\hline SELECT and & HadISST1.1 & $-0.52 \pm 0.19 * *$ & $0.38 \pm 0.15^{* *}$ & $0.36 \pm 0.16^{* *}$ & $-5.82 \pm 0.32 * * *$ & $-1.72 \pm 0.21 * * *$ & $-0.94 \pm 0.22 * * *$ \\
\hline Weighted & ERSST3b & $-0.51 \pm 0.18 * * *$ & $0.37 \pm 0.15^{* *}$ & $0.35 \pm 0.15^{* *}$ & $-5.61 \pm 0.31 * * *$ & $-1.65 \pm 0.21 * * *$ & $-0.95 \pm 021 * * *$ \\
\hline ALL and & HadISST1.1 & $-0.23 \pm 0.16$ & $0.51 \pm 0.12 * * *$ & $0.39 \pm 0.13^{* * *}$ & $-5.50 \pm 0.45 * * *$ & $-1.44 \pm 0.15^{* * *}$ & $-0.73 \pm 0.13 * * *$ \\
\hline Unweighted & ERSST3b & $-0.24 \pm 0.15$ & $0.48 \pm 0.11^{* * *}$ & $0.36 \pm 0.13^{* * *}$ & $-5.30 \pm 0.44 * * *$ & $-1.36 \pm 0.15^{* * *}$ & $-0.73 \pm 0.12 * * *$ \\
\hline ALL and & HadISST1.1 & $-0.22 \pm 0.16$ & $0.52 \pm 0.11^{* * *}$ & $0.43 \pm 0.13^{* * *}$ & $-5.30 \pm 0.33 * * *$ & $-1.31 \pm 0.15^{* * *}$ & $-0.58 \pm 0.16^{* * *}$ \\
\hline Weighted & ERSST3b & $-0.23 \pm 0.15$ & $0.49 \pm 0.11^{* * *}$ & $0.40 \pm 0.12 * * *$ & $-5.11 \pm 0.33 * * *$ & $-1.24 \pm 0.15 * * *$ & $-0.59 \pm 0.15 * * *$ \\
\hline
\end{tabular}

The presence of one, two, or three asterisks indicates whether the trends are significant at the 10,5 and $1 \%$ level, respectively (see Santer et al. 2000) 


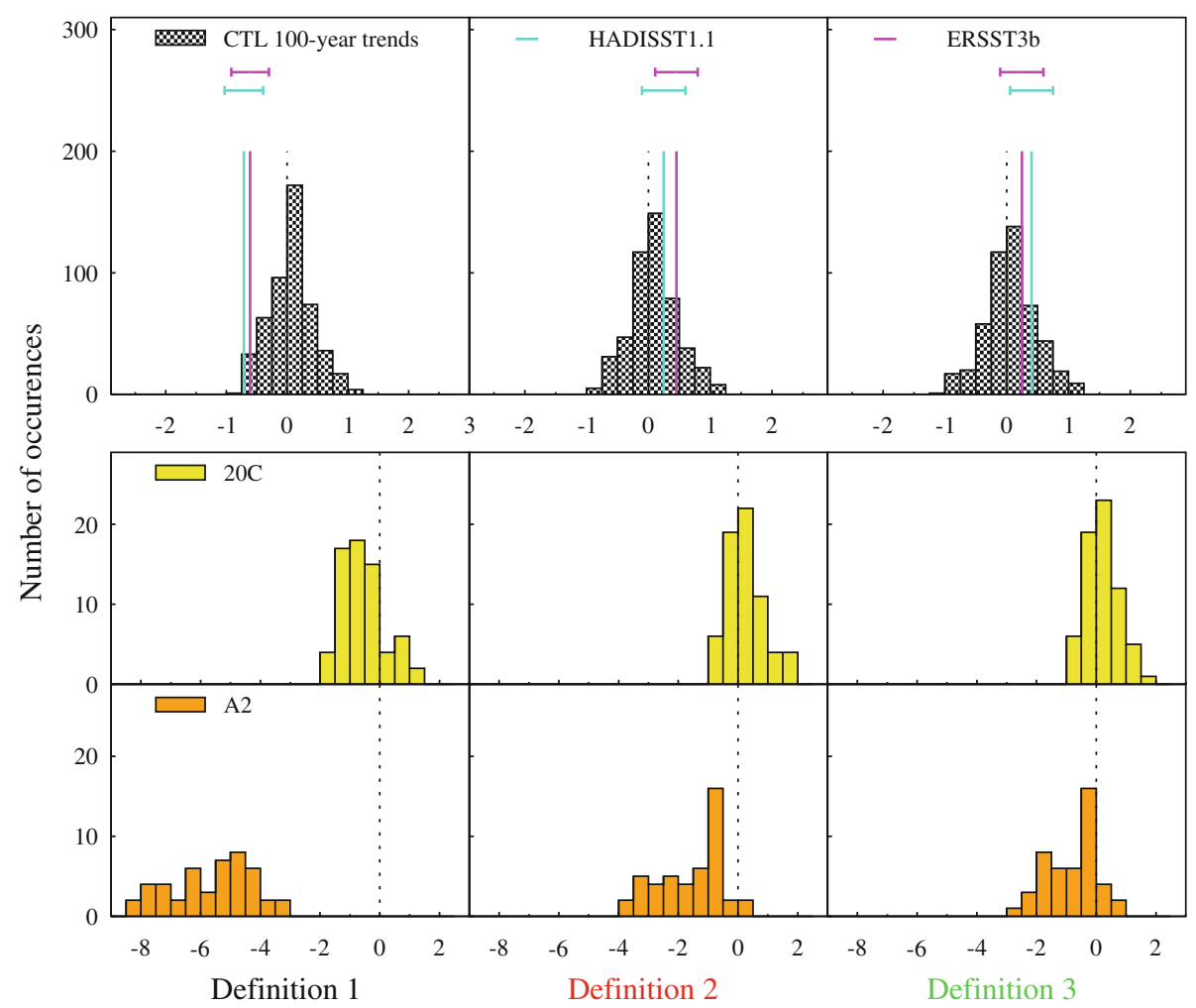

Fig. 5 Comparison between observed and simulated trends in PDO indices on the century time scale for definition 1 (left panel), 2 (middle panel) and 3 (right panel). Here, all HadISST1.1- and ERSST3b-derived PDO indices are included to account for observational uncertainties. Observed trends are computed over the period 1910-2009, the simulated historical trends over the period 1900-1999, and the future trends over the period 2000-2099. The

of the PDO region (relative to the globe) is evident in the observations, in two-thirds of the 33 20CEN realizations, and in all but one of the A2 realizations (Fig. 6).

\section{Summary and concluding remarks}

We have shown that the interpretation of changes in the PDO index can be problematic. If no global-mean SST signal is subtracted prior to the EOF analysis (our definition 1), the PDO index is contaminated with a significant anthropogenically-forced component. This component is detectable (on the century time scale) in both observed SST datasets examined here. It is also detectable in model simulations of historical and future climate change. It is unlikely, therefore, that the behavior of the observed $\mathrm{PDO}_{1}$ index is entirely due to natural internal variability.

The official definition of the PDO (our "definition 2") makes the implicit assumption that any anthropogenic influence on PDO behavior is completely removed by subtracting the time-evolving changes in global-mean SST from local SST changes in the PDO region. This is unlikely sampling distribution of unforced trends was obtained from a total of $2 \times 248$ overlapping 100-year segments of the CTL integrations. Sampling distributions of simulated historical (future) trends was obtained from the $2 \times 33(2 \times 23)$ SELECT 20CEN (A2) realizations. The vertical lines and error bars indicate the observed PDO trends obtained from the HadISST1.1 and the ERSST3b datasets and their standard errors

to be the case. Differences in warming rates appear towards the end of the twentieth century in two-thirds of the 20CEN runs, with the PDO region warming more rapidly than the global oceans. In the A2 simulations, these differences in warming rates are large and occur in almost all models, yielding twenty-first century $\mathrm{PDO}_{2}$ trends that are clearly distinguishable from internal climate variability. Our results suggest, therefore, that a residual anthropogenic signal is aliased into definition 2 of the PDO. Detection of this signal in the observed $\mathrm{PDO}_{2}$ indices depends on the timescale of the analysis: observed $\mathrm{PDO}_{2}$ changes over the full twentieth century are not significantly different from model-based noise estimates, but $\mathrm{PDO}_{2}$ changes over the last 32 years cannot be explained by internal variability alone. If model projections of future SST changes are reliable, anthropogenic contamination of the officiallydefined PDO index should become more apparent over the next several decades, as the differential warming of the North Pacific and global oceans continues.

Subtracting the time-evolving changes in "PDO-average" SSTs from the local SST changes prior to the EOF analysis (our definition 3) partially solves this "contamination" 


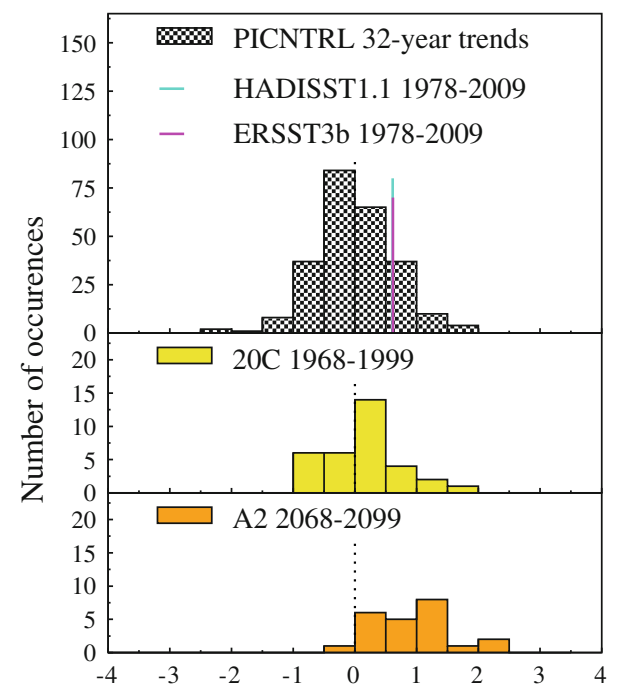

Fig. 6 Comparison between observed and simulated trends in differential warming between the PDO and global domains (in ${ }^{\circ} \mathrm{C} /$ century) on the 32-year time scale. Sampling distribution of unforced trends was obtained from a total of 248 overlapping 32-year segments of the SELECT CTL integrations. Sampling distributions of simulated historical (future) trends was obtained from the 33 (23) SELECT 20CEN (A2) realizations over the period 1968-1999 (2068-2099). A KS test indicates the distribution of A2 trends is statistically different (at the 5\% significance level) from that generated from internally generated variability. The 20CEN distribution and the 1978-2009 observed trends are not found to be significantly different from climate noise

problem. The anthropogenic component in the $\mathrm{PDO}_{3}$ index is much smaller in the case of the $\mathrm{PDO}_{1}$ and $\mathrm{PDO}_{2}$ indices. In the $\mathrm{PDO}_{3}$ index, this component arises because the pattern of SST response to greenhouse gas forcings is similar to the $\mathrm{PDO}_{3}$ pattern (and thus projects strongly onto the latter), but the SST changes in these two patterns are of opposite sign in the central "core" of the PDO region (compare Figs. 2c, 4a). The resultant negative trend in the $\mathrm{PDO}_{3}$ index is only conclusively distinguishable from internal climate variability in the A2-based $\mathrm{PDO}_{3}$ time-series. Even in the case of the $\mathrm{PDO}_{3}$ index, therefore, where the index is unaffected by differences between regional and global warming rates, there is a very real possibility that human activity may influences the statistical properties of "natural" modes of variability (see, e.g., Corti et al. 1999; Fedorov and Philander 2000; Shindell et al. 1999; Timmermann et al. 1999; Cubash et al. 2001; Palmer 2008).

Our results support previous research (Overland and Wang 2007) suggesting that the variability in North Pacific SST will be dominated by a warming trend rather than by PDO variability. As noted above, we also find (in our analysis of the A2 results) that this overall warming of the North Pacific is likely to have some spatial structure, with maximum warming in the central North Pacific.
Our study illustrates that North Pacific SST changes over the twentieth and twenty-first centuries have both internally-generated and externally-forced components, and that the strength of these components is dependent on the definition of the PDO index. Understanding both internal and external components is important in order to improve the decadal predictability of future changes in regional climate, droughts, and natural systems. Since PDO indices are often used to statistically remove "natural variability" effects from a variety of observational datasets, such noise removal exercises should be exercised with great care.

Acknowledgments We thank the international modeling groups for providing their data for the analysis, the Program for Climate Model Diagnosis and Intercomparison for collecting and archiving them, and the World Climate Research Program's Working Group on Coupled Modeling for organizing the model data analysis activity. We warmly thank David Pierce and Tim Barnett for their helpful comments, notably for the origin of the inter-definition differences. This work was performed under the auspices of the U.S. Department of Energy by Lawrence Livermore National Laboratory under Contract DOEAC52-07NA27344. A portion of this study was supported by the US Department of Energy, Office of Biological and Environment Research.

Open Access This article is distributed under the terms of the Creative Commons Attribution Noncommercial License which permits any noncommercial use, distribution, and reproduction in any medium, provided the original author(s) and source are credited.

\section{Appendix 1: observational datasets}

The HadISST1.1 (ERSTT3b) observational dataset is provided in the form of monthly mean data, spanning from January 1870 (1854) to December 2009 on a $1^{\circ} \times 1^{\circ}$ $\left(2^{\circ} \times 2^{\circ}\right)$ latitude/longitude grid. Reconstruction of SST anomalies involved a fitting to a set of spatial modes in ERSST3b dataset, and a two-stage reduced-space optimal interpolation procedure in the HadISST1.1 dataset. For both datasets, the land-sea mask is binary and ocean temperatures covered by sea-ice have been set to $-1.8^{\circ} \mathrm{C}$ before regridding (See Appendix 3.2). The sea-ice mask provided in HadISST1.1 is time-dependant.

\section{Appendix 2: modeling groups contributing to IPCC database}

This analysis relies on Coupled Model Intercomparison Project phase 3 (CMIP3) simulations performed for the Fourth Assessment Report of the Intergovernmental Panel for Climate Change (IPCC AR4). These simulations were made available to the scientific community through the U.S. Department of Energy's Program for Climate Model 
Diagnosis and Intercomparison (PCMDI) at Lawrence Livermore National Laboratory (http://www-pcmdi.llnl.gov). In this study, we selected a total of 17 different climate models that have been used to perform both 20CEN and A2 experiments (in IPCC terminology, these integrations are referred as "20c3m" and "sresa2", respectively). Multi 20CEN (A2) realizations exist for 11 (7) of the 17 models analyzed here. The realizations from a particular ensemble contain identical changes in external forcings but differ only in their initial conditions. This approach yields many different realizations of the climate "signal" (the response to the imposed forcing changes) plus climate noise. The number of realizations and the name of modeling group are provided for each model in Table 1. The eight SELECT models are CCCma-CGCM3.1 (T47), GFDL-CM2.0, GFDL-CM2.1, MIROC3.2(medres), MIUB/ECHO-G, MRI-CGCM2.3.2, CCSM3.0 and UKMO-HadCM3). Different performance tests (Latif and Barnett 1996; Nakamura et al. 1997; Sun and Wang 2006) could have led to a slightly different set of selected models. More details on the external forcings used in the 20CEN experiments are provided in Santer et al. (2006).

\section{Appendix 3: details on the calculation of PDO indices}

\section{Description of the method}

The official PDO time-series relies on "residual" monthlymean SST anomalies in the North Pacific region, poleward to $20^{\circ} \mathrm{N}$. The PDO region of consideration in this study extends from $20^{\circ} \mathrm{N}$ to $60^{\circ} \mathrm{N}$ and from $245^{\circ} \mathrm{W}$ to $115^{\circ} \mathrm{W}$. The calculation of the PDO indices requires a three-step approach. Step 1 includes regridding and masking appropriately all data (see Appendix 3.2). Step 2 consists in an EOF analysis to obtain the S-PDOP pattern. This EOF analysis accounts for the smaller area weight of the northern latitudes (due to converging meridians) by weighting the gridded SSTs by the square root of the cosine of the latitude. The last step involves the projection of SST anomalies from the various observational datasets and climate model simulations onto this S-PDOP. Steps 2 and 3 are reiterated for each definition. This procedure closely mimics the official methodology, which relies on one unique S-PDOP (based on the period 1900-1993) and allows for a monthly update of the PDO time-series and possible changes in employed observational SST datasets, without the modification of past PDO index values. For instance, the official PDO index has been derived from an older version of the HadISST1.1 dataset for the period 1900-2002, but extended after 2002 using the optimally interpolated SSTs dataset (Reynolds and Smith 1995). We can also note that this technique permits to obtain PDO indices from all simulations, independently of their ability to successfully capture the spatial characteristics associated with PDO. The question of whether the PDO would have a different pattern in the twenty-first century is however not addressed here. The analysis and interpretation of the spatial PDO pattern obtained from individual IPCC models projections are discussed elsewhere (Bond et al. 2006).

Regridding and masking of data

Each observational and model dataset is provided with a land-sea mask on its original grid. The projection of the variety of simulated and observational SST anomalies onto common observed S-PDOP patterns requires that all data share the same horizontal grid and a common land-sea mask. We followed the following strategy: (1) we regridded data from all observational datasets and model experiments to a common T42 horizontal resolution, in taking appropriately the mask into account, (2) additionally, in order to mimic the observational datasets, all regridded SSTs inferior to the threshold of $-1.8^{\circ} \mathrm{C}$ in the climate simulations have been given the $-1.8^{\circ} \mathrm{C}$ value to represent sea-ice. In the case of HadISST1.1, the time-dependant seaice mask has been regridded first, then this time-dependant sea-ice mask has been geometrically averaged along the time-axis to provide a time-independent sea-ice mask, (3) to obtain a final land-sea mask common to all datasets, all regridded masks have been averaged geometrically. The final mask excludes any gridpoint that is covered entirely by land in at least one dataset.

\section{Appendix 4: sensitivity testing}

Sensitivity of observed PDO to the base period

Here, we investigated the stability of the S-PDOP pattern over time using the dataset with the longest record (ERSST3b). For each definition, we determined S-PDOP using 12 different overlapping 50 years base periods (1860-1909, 1870-1919, 1960-2009 and the additional 1900-1993 period). Figure 7a displays the spatial pattern correlations obtained with the first base period (1860-1909). S-PDOP ${ }_{3}$ and S-PDOP ${ }_{2}$ are the least sensitive to the base period used. In contrast, the spatial variability in the S-PDOP is the most pronounced when definition 1 is used. Figure 7b shows that the trend in ERSST3b-based $\mathrm{PDO}_{1}$ over the period 1900-2009 varies greatly with the base period chosen. It also shows that the trend is proportional to the spatial average of the corresponding S-PDOP eigenvectors. This indicates the large influence of projecting a slowly-evolving warming onto an unstable S-PDOP ${ }_{1}$ 


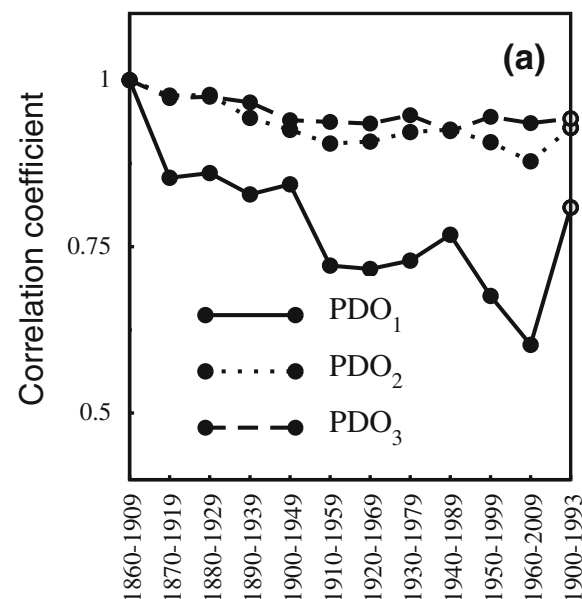

Fig. 7 a For each definition, centered spatial pattern correlation between the S-PDOP based on different overlapping 50-years base periods (indicated on the $x$-axis) and the S-PDOP based on the first tested base period (1860-1909). b Scatter plots between the spatial average of the S-PDOP ${ }_{1}$ eigenvectors $(x$-axis) and their corresponding

pattern. Likewise, the trends in projected future PDO timeseries are sensitive to the base period in definition 1 and relatively insensitive to the base period in definition 3 (not shown).

Sensitivity of the simulated PDO to model screening and weighting

The results presented in the main manuscript are inferred from the eight SELECT climate models. Each model has been given the same weight, independently of its number of realizations. We tested the sensitivity of the results using two sets of models (using either the 8 SELECT models or the total of 17 models), and two model weighting options (equally-weighted, or weighted as a function of the number of realizations). We found that the results are not very sensitive to those processing options (Table 3), with one exception: when all models are used, the negative 20CEN trends in $\mathrm{PDO}_{1}$ are not statistically significant.

\section{Appendix 5: statistical tests}

Comparison of observed and unforced trends

The model-derived estimate of the two-tailed 95\% (90\%) confidence interval natural internal variability is calculated as $1.960(1.644) \times \mathrm{sE}$, where $\mathrm{sE}$ is the standard error of the sampling distribution of the unforced trends. We consider that an observed trend is inconsistent with the simulated response to internal climate variability at the 5\% (10\%) level when its estimate exceeds this $95 \%$ (90\%) confidence interval.

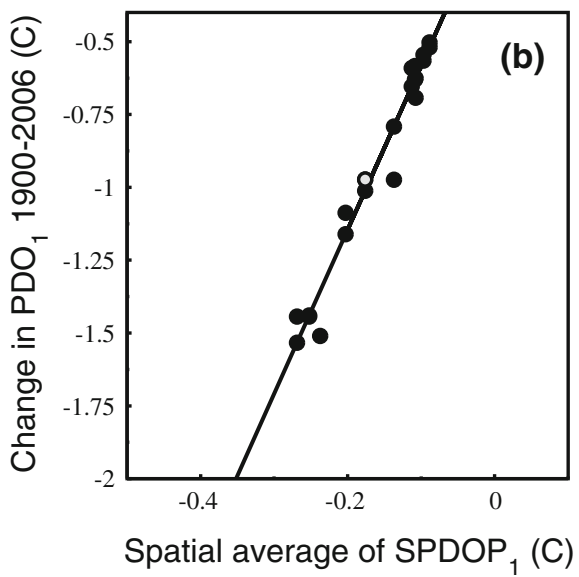

change in $\mathrm{PDO}_{1}$ over the period 1900-2006 (y-axis). Each circle represents the result obtained for a base period indicated in Fig. a. The result obtained for the 1900-1993 base period is represented by an open circle in both panels

Comparison of unforced and anthropogenically forced trends

We use a Kolmogorov-Smirnov (KS) test to determine whether the trend distributions inferred from the 20CEN (or A2) and CTL experiments differ significantly (Press et al. 1992). The KS test consists at comparing the cumulative distribution $A(x)$ of the 20CEN (or A2) trends with the distribution $C(x)$ of the CTL unforced trends. For the differential warming between the PDO and global domains, we test the null hypothesis that $A(x) \geq C(x)$. For the PDO time-series themselves, the null hypothesis is that $A(x) \leq C(x)$. We compute the maximum distance between $C(x)$ and $A(x)$ and the associated one-tailed $p$-value.

\section{References}

Biondi F, Gershunov A, Cayan DR (2001) North Pacific decadal climate variability since AD 1661. J Clim 14:5-10

Bond NA, Overland JE, Wang M (2006) IPCC model projections of North Pacific climate variability. Eos Trans. AGU, 87(52), Fall Meet Suppl, Abstract OS24C-07

Bonfils C, Santer BD, Pierce DW, Hidalgo HG, Bala G et al (2008) Detection and attribution of temperature changes in the mountainous western United States. J Clim 21:6404-6424

Cayan DR, Kammerdiener SA, Dettinger MD, Caprio JM, Peterson DH (2001) Changes in the onset of spring in the western United States. Bull Amer Meteor Soc 82:399-415

Corti S, Molteni F, Palmer TN (1999) Signature of recent climate change in frequencies of natural atmospheric circulation regimes. Nature 398:799-802

Cubash U, Meehl GA, Boer GJ, Stouffer RJ, Dix M, Noda A, Senior CA, Raper S, Yap KS (2001) Projections of future climate change, chap. 9. In: Houghton J et al (eds) Climate change 2001. 
The scientific basis. Intergovernmental Panel on Climate Change, Cambridge University Press, Cambridge

Davis RE (1976) Predictability of sea surface temperature and sea level pressure anomalies over the North Pacific Ocean. J Phys Oceanogr 6:249-266

Fedorov AV, Philander SG (2000) Is El niño changing? Science 288:1997-2002

Hare SR (1996) Low frequency climate variability and salmon production. A dissertation by Hare SR submitted in partial fulfillment of the requirements for the degree of Doctor of Philosophy University of Washington

Hunt BG (2008) Secular variation of the pacific decadal oscillation, the North Pacific oscillation and climatic jumps in a multimillennial simulation. Clim Dyn 30:467-483

Knowles N, Dettinger MD, Cayan DR (2006) Trends in snowfall versus rainfall in the Western United States. J Clim 19:4545-4559

Latif M, Barnett TP (1996) Decadal climate variability over the North Pacific and North America: dynamics and predictability. J Clim 9:2407-2423

Mantua N, Hare S (2002) The Pacific decadal oscillation. J Oceanogr 58:35-44

Mantua N, Hare S, Zhang Y, Wallace J, Francis R (1997) A Pacific interdecadal oscillation with impacts on salmon production. Bull Am Met Soc 58:1069-1079

McCabe GJ, Dettinger MD (2002) Primary modes and predictability of year-to-year snowpack variations in the western United States from teleconnections with Pacific Ocean climate. J Hydrometeorol 3:13-25

McGregor S, Holbrook MJ, Power SB (2007) Interdecadal sea surface temperature variability in the equatorial Pacific Ocean. Part I: the role of off-equatorial wind stresses and oceanic Rossby waves. J Clim 20:2643-2658

Meehl GA, Hu A (2006) Megadroughts in the Indian monsoon region and southwest North America and a mechanism for associated multi-decadal Pacific sea surface temperature anomalies. J Clim 19:1605-1623

Meehl GA et al (2007) Global Climate Projections. In: Solomon S et al (eds) Climate change 2007: the physical science basis, contribution of Working Group I to the fourth assessment report of the intergovernmental panel on climate change. Cambridge University Press, Cambridge

Meehl GA, Hu A, Santer BD (2009) The mid-1970s climate shift in the Pacific and the relative roles of forced versus inherent decadal variability. J Clim (In press)

Mote PW (2003) Trends in snow water equivalent in the Pacific Northwest and their climatic causes Declining mountain snowpack in western North America. Geoph Res Lett 1601. doi: 10.1029/2003GL017258

Nakamura H, Lin G, Yamagata T (1997) Decadal climate variability in the North Pacific during the recent decades. Bull Amer Meteor Soc 78:2215-2225

Neal EG, Walter MT, Coffeen C (2002) Linking the pacific decadal oscillation to seasonal stream discharge patterns in Southeast Alaska. J Hydrol 263:188-197

Overland JE, Wang M (2007) Future climate of the North Pacific Ocean. Eos Trans Am Geophys Union 88:178-182

Palmer T (2008) Introduction in CLIVAR exchanges-natural modes of variability under anthropogenic climate change. Southampton,
UK, International CLIVAR Project Office, $32 \mathrm{pp}$. (CLIVAR Exchanges, No. 46 (Vol.13 No.3) (available at http://eprints. soton.ac.uk/55670)

Pierce DW, Barnett TP, Latif M (2000) Connections between the Pacific Ocean tropics and midlatitudes on decadal time scales. J Clim 13:1173-1194

Pierce DW, Barnett TP, Hidalgo GH, Das T, Bonfils C, Santer BD et al (2008) Attribution of declining western U.S. snowpack to human effects. J Clim 21:6425-6444

Power S, Casey T, Folland C, Colman A, Mehta V (1999) Interdecadal modulation of the impact of ENSO on Australia. Clim Dyn 15:319-324

Press WH, Flannery BP, Teukolsky SA, Vetterling WT (1992) "Kolmogorov-Smirnov Test." In: Numerical recipes in FORTRAN: The art of scientific computing, 2nd ed. Cambridge University Press, Cambridge, pp. 617-620

Rayner NA, Brohan P, Parker DE, Folland CK, Kennedy J, Vanicek M, Ansell T, Tett SFB (2006) Improved analyses of changes and uncertainties in sea surface temperature measured in situ since the mid nineteenth century. J Clim 19:446-469

Reynolds RW, Smith TM (1995) A high-resolution global sea surface temperature climatology. J Clim 16:1571-1583

Santer BD, Wigley TML, Boyle JS, Gaffen DJ, Hnilo JJ, Nychka D, Parker DE, Taylor KE (2000) Statistical significance of trends and trend differences in layer-average atmospheric temperature time series. J Geophys Res 105:7337-7356

Santer BD, Wigley TML, Gleckler PJ, Bonfils C, Wehner MF et al (2006) Forced and unforced ocean temperature changes in Atlantic and Pacific tropical cyclogenesis regions. Proc Natl Acad Sci 103:13905-13910

Sato M, Hansen JE, Lacis A, McCormick MP, Pollack JB (1993) Aerosol optical depths, 1850-1990. J Geophys Res 98: 22987-22994

Schoennagel T, Veblen TT, Romme WH, Sibold JS, Cook ER (2005) ENSO and PDO variability affect drought-induced fire occurrence in rocky mountain subalpine forests. Ecol Appl 15: 2000-2014

Shindell DT, Miller RL, Schmidt GA, Pandolfo L (1999) Simulation of recent northern winter climate trends by greenhouse-gas forcing. Nature 399:452-455

Smith TM, Reynolds RW, Peterson C, Lawrimore J (2008) Improvements to NOAA's historical merged land-ocean surface temperature analysis (1880-2006). J Clim 21:2283-2296

Stewart IT, Cayan DR, Dettinger MD (2005) Changes to earlier streamflow timing across Western North America. J Clim 18:1136-1155

Sun J, Wang H (2006) Relationship between Arctic Oscillation and Pacific Decadal Oscillation on decadal timescale. Chin Sci Bull 51:75-79

Thompson DWJ, Kennedy JJ, Wallace JM, Jones PD (2008) A large discontinuity in the mid-twentieth century in observed globalmean surface temperature. Nature 453:646-649

Timmermann A, Oberhuber J, Bacher A, Esch M, Latif M, Roeckner E (1999) Increased El Nino frequency in a climate model forced by future greenhouse warming. Nature 398:694-697

Trenberth KE, Hurrell JW (1994) Decadal atmosphere-ocean variations in the Pacific. Clim Dyn 9:303-319

Zhang Y, Wallace JM, Battisti DS (1997) ENSO-like interdecadal variability: 1900-93's. J Clim 10:1004-1020 